\title{
Deletion of Nf1 in Neurons Induces Increased Axon Collateral Branching after Dorsal Root Injury
}

\author{
Mario I. Romero, ${ }^{\star}$ Lu Lin, ${ }^{\star}$ Mark E. Lush, Lei Lei, Luis F. Parada, and Yuan Zhu \\ Department of Developmental Biology and Kent Waldrep Foundation Center for Basic Neuroscience Research on Nerve Growth and Regeneration, \\ University of Texas Southwestern Medical Center, Dallas, Texas 75390-9133
}

\begin{abstract}
Ras-mediated signaling pathways participate in multiple aspects of neural development and function. For example, Ras signaling lies downstream of neurotrophic factors and Trk family receptor tyrosine kinases to regulate neuronal survival and morphological differentiation, including axon extension and target innervation. Neurofibromin, the protein encoded by the tumor suppressor gene Nf1, is a negative regulator of Ras [Ras-GAP (GTPase-activating protein)], and we previously demonstrated that $N f 1$ null embryonic sensory and sympathetic neurons can survive and differentiate independent of neurotrophin support. In this report, we demonstrate that $N f 1$ loss in adult sensory neurons enhances their intrinsic capacity for neurite outgrowth and collateral branching in vitro and in vivo after dorsal root injury. In contrast to the permanent sensory deficits observed in control mice after dorsal rhizotomy, neuron-specific Nfl mutant mice spontaneously recover proprioceptive function. This phenomenon appears to be mediated both by a cell-autonomous capacity of spared NfI-I- DRG neurons for increased axonal sprouting, and by non-cell-autonomous contribution from NfI-I- neurons in the denervated spinal cord.
\end{abstract}

Key words: neurofibromin; collateral branching; dorsal rhizotomy; functional recovery; NT-3; regeneration

\section{Introduction}

Regeneration failure in the adult CNS results in permanent sensory-motor deficits in part attributable to postnatal reduction in the intrinsic growth capacity of neurons (Bomze et al., 2001), along with a growth-inhibitory environment present at the injury site, primarily mediated by chondroitin proteoglycans (Morgenstern et al., 2002) and myelin-associated inhibitors (Chen et al., 2000; GrandPre et al., 2000; Wang et al., 2002). Traditionally, repair strategies have focused on the modification of the extracellular milieu through cellular grafting (McDonald et al., 1999; Takami et al., 2002; Teng et al., 2002), blockade of inhibitory molecules (Merkler et al., 2001; Bradbury et al., 2002; GrandPre et al., 2002), addition of growth-enticing factors (Ramer et al., 2000; Romero et al., 2001), or combinations thereof ( $\mathrm{Lu}$ et al., 2004; Pearse et al., 2004; Fouad et al., 2005). These efforts have

Received May 15, 2006; revised Jan. 2, 2007; accepted Jan. 8, 2007.

This work was supported by the Christopher Reeve Foundation (M.I.R., L. Lin, L.F.P.) and by the National Institute of Neurological Disorders and Stroke and the Department of Defense (L.F.P.). We thank Russ Daniel for technical assistance and Steven McKinnon for animal husbandry and genotyping support. We thank members of the Parada Laboratory for helpful discussions, particularly Michael Rubin, Joshua Ransom, Douglas Benson, and Steve Kernie.

*M.I.R. and L. Lin contributed equally to this work.

Correspondence should be addressed to Dr. Luis F. Parada at the above address. E-mail: luis.parada@utsouthwestern.edu.

M. I. Romero's present addresses: Department of Neurology, University of Texas Southwestern Medical Center, Dallas, TX 75390-9036; and Division of Regenerative Neurobiology, Texas Scottish Rite Hospital for Children, 2222 Welborn Street, Dallas, TX 75219.

L. Lei's present address: School of Life Sciences, Arizona State University, P.0. Box 874501, Tempe, AZ 85287-4501.

Y. Zhu's present address: Division of Molecular Medicine and Genetics, Departments of Internal Medicine and Cell and Developmental Biology, University of Michigan Medical School, Ann Arbor, MI 48109.

DOI:10.1523/JNEUROSCI.4363-06.2007

Copyright $\odot 2007$ Society for Neuroscience $\quad$ 0270-6474/07/272124-11\$15.00/0 provided modest but promising anatomical and functional recovery (Horner and Gage, 2000; Schwab, 2002).

Recent evidence has demonstrated that the intrinsic growth capacity of injured neurons can be modified to a growthpromoting state, either by exposure to a preconditioning injury (Neumann and Woolf, 1999), the induced expression of growthassociated molecules (Bomze et al., 2001; Neumann et al., 2002; Qiu et al., 2002), or preexposure to neurotrophic factors (Cai et al., 1999). Neurotrophins bind to their high-affinity tyrosine kinase receptors (Trks), and activate a number of downstream effectors. In sensory neurons, this cascade mediates both neuronal survival (Klesse and Parada, 1998; Klesse et al., 1999) and axonal growth (Lentz et al., 1999; Markus et al., 2002b). Membranebound Ras proteins cycle between the inactive GDP- and the active GTP-bound conformations, and activated intermediates of the Ras-mitogen-activated protein kinase kinase (MEK)nitrogen activated protein kinase (MAPK) signaling cascade mimic neurotrophin treatment (Markus et al., 2002a). Congruently, loss of function in the Ras-GAP (GTPase-activating protein) neurofibromin, a negative Ras regulator encoded by the neurofibromatosis type 1 (Nf1) tumor suppressor gene, endows embryonic sensory neurons with independence from neurotrophic factors for survival and differentiation (Vogel et al., 1995; Zhu et al., 2001). Here, we provide evidence that constitutive Ras activation in neurons via $N f 1$ loss enhances their intrinsic capacity for axonal growth and collateral branching after injury. The outcome is one of partial functional recovery in an established injury paradigm.

\section{Materials and Methods}

Animals

The generation of homozygous Nf1flox/flox, SynapsinI-Cre, and Nf1flox/flox/Synapsin I-Cre (Nf1SynIKO) mice has been reported and 
fully characterized previously (Zhu et al., 2001). Cre-negative animals are phenotypically indistinguishable and thus were pooled for controls. Because of the small size of NfISynIKO, Smad-3 mutants (Zhu et al., 1998) that are also small were included as size controls. Genotypes were confirmed by tail DNA PCR.

\section{Cell culture}

Cultures were prepared from embryonic day 13.5 (E13.5) dorsal root ganglia (DRGs) of Nflflox/flox and Nf1SynIKO mice. DRGs were cleaned from connective tissue, incubated in $0.125 \%$ trypsin/collagenase for $30 \mathrm{~min}$ at $37^{\circ} \mathrm{C}$, and mechanically dissociated by gentle trituration in Hanks buffer (Invitrogen, San Diego, CA). Cells were cultured in Neurobasal/B27/L-glutamine media (Invitrogen) alone, or supplemented with either NGF (10 ng/ml; Invitrogen) or NT-3 $(20 \mathrm{ng} / \mathrm{ml}$; Sigma, St. Louis, MO) as indicated. Cells were plated onto Lab-Tek chamber slides coated with poly-L-lysine or poly-D-ornithine only (2 $\mathrm{mg} / \mathrm{ml}$; Sigma) or with poly-L-lysine-laminin (10 $\mu \mathrm{g} / \mathrm{ml}$; Invitrogen). Cultures were incubated for $36-48 \mathrm{~h}$ at $37^{\circ} \mathrm{C}$ in a humidified atmosphere containing $5 \% \mathrm{CO}_{2}$.

\section{Explant culture}

Adult DRGs were dissected and whole explants were embedded in Matrigel (BD Biosciences, Bedford, MA) and cultured in Neurobasal-A/ B27/L-glutamine media. Cultures were maintained under conditions of no neurotrophin up to $48-72 \mathrm{~h}$. Mix-match coculture experiments were done exposing lumbar spinal cords cut into $500 \mu \mathrm{m}$ slices and DRGs obtained from $\mathrm{Nf1flox} /$ flox or Nf1SynKO adult mice, coembedded in Matrigel and cultured in Neurobasal-A/B27/L-glutamine media for $48 \mathrm{~h}$. Assessment of cell death in cultured spinal cord slices was determined by labeling dead cells with propidium iodide (PI) (10 $\mu \mathrm{M}$; Invitrogen) for $1 \mathrm{~h}$ at $37^{\circ} \mathrm{C}$ before imaging (Adamchik et al., 2000; Krassioukov et al., 2002). The optical densitometry of the incorporated fluorescence was compared with that obtained after inducing cell death by cooling $\left(4^{\circ} \mathrm{C}\right.$ for $\left.48 \mathrm{~h}\right)$ in the presence of PI.

\section{Quantification of neurite growth}

Axon length was determined in phase contrast images acquired using a $20 \times$ objective at different focal planes. The axons were traced and measured using the MetaMorph Imaging software (Universal Imaging, West Chester, PA). Approximately 50 axons per explant were counted in each experiment, and four explants for each genotype were included in two separate experiments. Axons were defined as neurites longer than $20 \mu \mathrm{m}$. The analyst was blind to the treatments and genotypes. Statistical significance was considered if $p \leq 0.05$ using a two-tailed Student's $t$ test or one-way ANOVA.

\section{Immunohistochemistry}

Cells and explants were fixed with $4 \%$ ice-cold paraformaldehyde solution for 30-45 min. Cells or tissues were incubated with a combination of primary antibodies overnight at $4^{\circ} \mathrm{C}$. Antibodies used were as follows: LacZ (1:500; ICN, Aurora, OH), TrkC (1:200; gift from Dr. L. Reichardt, University of California, San Francisco, CA), neurofilament 200 (NF200) (1:1000; Sigma), calcitonin gene-related peptide (CGRP) (1:2000; Sigma), cholera toxin $\beta$-subunit (CTB) (1:2000 List Biological, Campbell, CA), $\beta$-tubulin (1:200; Sigma), and GFAP (1:500; Dako, Carpinteria, CA). Visualization was achieved by tissue incubation in fluorescent or biotinylated secondary antibodies. Biotin-labeled tissue was processed further with the Vectastain Elite ABC reagents (Vector, Burlingame, CA) and developed by $\mathrm{DAB}$ colorimetric reaction. Immunofluorescence was visualized after $1 \mathrm{~h}$ incubation with appropriate Cy2-, Cy3-, and Cy5conjugated secondary antibodies (1:400; Jackson ImmunoResearch, West Grove, PA) at room temperature. The staining was then evaluated with epifluorescence and confocal (Zeiss 510; Zeiss, Oberkochen, Germany) microscopy.

\section{$\beta$-Gal staining/DAB immunocytochemistry}

Detection of $\beta$-gal activity was visualized enzymatically by incubation of the tissue sections in $\mathrm{X}-\mathrm{Gal} /$ ferricyanide/ferrocyanide solution, which produces a blue precipitate, and subsequently processed for immunocy-
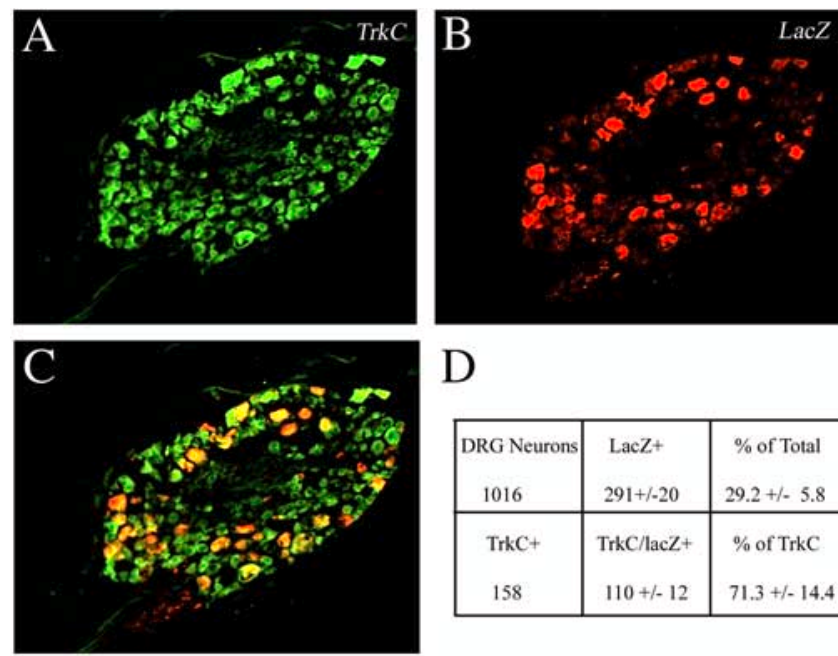

$\mathrm{D}$
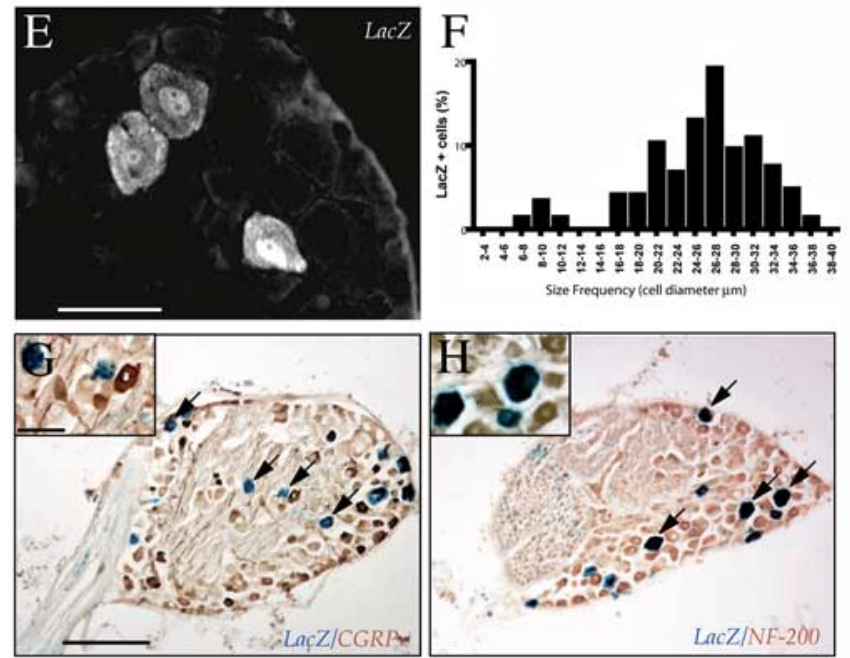

Figure 1. Cre-mediated inactivation of Nf1 in proprioceptive DRG neurons. $A-C$, Colabeling of TrkC $(\boldsymbol{A})$ and LacZ $(\boldsymbol{B})$ in thoracic and lumbar DRG neurons in adult SynlCre/Rosa26 mice, reveals that the majority of $\mathrm{LaCZ}+$ cells are $\operatorname{Trk} C+$, and thus proprioceptive in nature $(\boldsymbol{C}$; merged image). $\boldsymbol{D}$, Quantification of $1016 \mathrm{DRG}$ neurons from three different ganglia shows that $29.2 \pm 5.8 \%$ of them are LacZ + , and thus undergo Cre-mediated recombination. $\boldsymbol{E}, \boldsymbol{F}$, Size distribution analysis of $\mathrm{LaCZ}+$ cells indicates that the majority of the recombined cells are the size of proprioceptive neurons ( $>22 \mu \mathrm{m}$ in diameter). $\mathbf{G}, \boldsymbol{H}$, Colocalization of LacZ with NF200 (la proprioceptive cells) ( $\boldsymbol{H}$, arrows), but not with CGRP (C-type nocioceptive neurons) ( $\boldsymbol{G}$, arrows) further confirms the proprioceptive nature of most Cre-recombined DRG neurons. Scale bars: $\boldsymbol{E}, 50 \mu \mathrm{m} ; \boldsymbol{G}, 200 \mu \mathrm{m} ; \boldsymbol{G}$, inset, $50 \mu \mathrm{m}$.

tochemical detection of CGRP or NF200 with DAB colorimetric reaction, which produces a brown-colored product.

\section{$D R G$ cell size distribution analysis}

Serial cryosection $(15 \mu \mathrm{m})$ of DRGs from SynICre/Rosa26 reporter mice were processed for LacZ immunostaining (1:500; rabbit anti- $\beta$-Gal; Chemicon, Temecula, CA). In cross section, sensory neurons containing a clearly visible nucleus and nucleolus were digitalized and their soma diameter evaluated using the AxioVision imaging software.

\section{Animal surgery}

Anesthetized (ketamine, $70 \mathrm{mg} / \mathrm{kg}$; Dormitor, $0.33 \mathrm{mg} / \mathrm{kg}$, i.p.) adult mice underwent unilateral hemilaminectomy to expose the L3-L6 lumbar dorsal roots. These fibers relay sensory information to the spinal cord from the hindlimb through the sciatic nerve, and collateralize in the dorsal spinal cord anterior-posterior for several segments. Dorsal rhyzotomies normally involve injuring the L3-L6 dorsal roots, thus removing sensory inputs from the hindlimb to the spinal cord. Crush injury allows spontaneous regeneration within the PNS compartment, but will nor- 
mally stop at the dorsal root entry zone (DREZ) (PNS-CNS interface). Cut and ligated roots are prevented from any regeneration (Romero et al., 2001). We concentrated on L4-L5 roots, which carry the majority of the primary hindlimb sensory afferents, and allowed us to test the effect of $\mathrm{Nf1}$ loss in CNS regeneration. Distinction between L4-L5 regeneration and collateral sprouting from L3 was achieved by transecting L6 in all animals. Therefore, the lumbar spinal cord in L4-L5 crushed injured animals are expected to bear axons from $\mathrm{L} 3 \mathrm{col}-$ lateral branches into the denervated area, as well as L4-L5 axons that might have regenerated through the DREZ into the spinal cord. In sharp contrast, animals with cut and ligated L4-L5 are expected to have only L3 afferents into the lumbar spinal cord at the L4-L5 entry levels, because L4-L6 are prevented from regenerating in these animals. Six experimental groups were tested in nine independent experiments: control sham $(n=4)$, control crushed $(n=17)$, control cut $(n=2), N f 1$ SynIKO crushed $(n=13), N f 1$ SynIKO cut $(n=7)$, and Smad3 $-/-$ crushed $(n=2)$.

Visualization of the proprioceptive sensory afferents was achieved through transganglionic tract-tracing performed in a cohort of these animals through microinjection of CTB (1\%; List Biological) into the sciatic nerve. The animals were perfused transcardially with saline buffer and $4 \%$ paraformaldehyde, $4 \mathrm{~d}$ after the CTB injection. Spinal cords and DRGs were removed, postfixed, and cryoprotected overnight in $30 \%$ sucrose at $4^{\circ} \mathrm{C}$. Frozen sections were cut at $20-30 \mu \mathrm{m}$ for subsequent staining.

\section{Behavioral analysis}

Grid walking. Behavioral assessment for regeneration of proprioceptive axons was done by measuring the accuracy of paw placement on a grid runway as described previously (Romero et al., 2001). The animals were videotaped making two complete crossings per trial. Individuals blinded to the treatment scored foot placement accuracy by analyzing the video in slow motion. Accurate placement of the hindpaw on the pegs was scored as a correct. The percentage of correct foot placements per trial was calculated and averaged for the two trials.

Toe spread index. Footprints of mice were recorded in a $90-\mathrm{cm}-$ long and 8-cm-wide runway on plain paper after the hindpaws had been painted with ink. Before the actual experiment, the animals were trained to walk through the runway several times. The traces left by the mice were measured in $8 \mathrm{~d}$ intervals from days 8 to 40 after surgery. The toe spread was estimated as the distance between the first and the fifth toes, subsequently; the toe-spread index was calculated as a function of the contralateral noninjured paw. Raw data were analyzed by ANOVA followed by Fisher's PLSD post hoc test (StatView 4.5; Abacus Concepts, Calabasas, CA).

\section{Tissue extraction and Western blotting}

Cortex, cerebellum, spinal cord, and DRGs were dissected from 8-weekold control or Nf1SynIKO mice ( $n=4$ each) and frozen in liquid nitrogen. Whole-cell proteins were extracted and subjected to Western blot as described previously (Zhu et al., 2001). Briefly, tissues were homogenized in radioimmunoprecipitation assay buffer $(50 \mathrm{ml}$ Tris- $\mathrm{HCl}, \mathrm{pH} 7.4,1 \%$ NP-40, 0.25\% Na-deoxycholate, $150 \mathrm{~mm} \mathrm{NaCl}, 1 \mathrm{~mm}$ EDTA, $1 \mathrm{~mm}$ $\mathrm{Na}_{3} \mathrm{VO}_{4}, 1 \mathrm{~mm} \mathrm{NaF}, 1$ tablet/10 ml Complete Mini; Roche, Indianapolis, $\mathrm{IN})$ at $0.1 \mathrm{~g}$ tissue weight $/ \mathrm{ml}$. The solutions were incubated on ice for 30 min and centrifuged at $14,000 \mathrm{rpm}$ for $20 \mathrm{~min}$ at $4^{\circ} \mathrm{C}$. Supernatant was collected and protein concentration was determined by the BCA Protein Assay kit (Pierce, Rockford, IL). Primary antibodies used for blotting were phospho-Erk1/2 (1:1000; Cell Signaling Technology, Beverly, MA), Erk1/2 (1:1000; Cell Signaling Technology), phospho-Akt (1:1000; Cell Signaling Technology), Akt (1:1000; Cell Signaling Technology), phospho-Gsk3 $\beta$ (1:1000; Cell Signaling Technology), and Gsk3 $\beta$
(1:1000; Cell Signaling Technology). Secondary antibodies used were HRP anti-rabbit (1:5000; Santa Cruz Biotechnology, Santa Cruz, CA). Immunoreactivity was detected with ChemiGlow West reagent (Alpha Innotech, San Leandro, CA), and densitometry analysis was performed with the Kodak 1D Image Analysis Software (Kodak, Rochester, NY).

\section{Results \\ Cre-mediated inactivation of $N f 1$ in proprioceptive DRG neurons}

E13.5 DRG neurons with germline or cre-mediated Nf1 inactivation survive and differentiate in the absence of neurotrophic support (Vogel et al., 1995; Zhu et al., 2001). Through the use of a Synapsin I promoter driven Cre transgene, a mouse line (Nf1SynIKO) that lacks Nf1 in the majority of CNS neurons was generated (Zhu et al., 2001). To examine whether Synapsin I-Cre is expressed in sensory neurons in these mice, visualization of Cre-expressing neurons in DRGs was evaluated by crossing Synapsin I-Cre animals with Rosa26-stop-lacZ Cre reporter mice (Soriano, 1999; Zhu et al., 2001). These studies revealed that, in DRGs and trigeminal ganglia, only a subset of neurons stain for $\beta$-galactosidase and thus contain Cre activity. The majority of sensory neurons express one of the three neurotrophin receptors, TrkA, TrkB, or TrkC (Liebl et al., 1997; Markus et al., 2002b). Double immunofluorescence for LacZ (Fig. 1B) and TrkC (Fig. $1 A$ ) demonstrated that $71 \%$ of the $\mathrm{TrkC}+$ neurons coexpress LacZ (Fig. $1 C, D$ ). Thus, in Nf1SynIKO mice, a majority of proprioceptive neurons have Cre activity and are expected to undergo Nf1 deletion. This result was independently confirmed by distribution analysis of DRG perikaryal diameter of LacZexpressing cells. In DRGs, Ia proprioceptive sensory neurons represent the majority of histologically distinguishable largediameter neurons, whereas small-diameter neurons are nociceptive and express TrkA (Averill et al., 1995; Molliver et al., 1995). A majority (73.97\%) of LacZ-positive neurons exhibit large diameter $(>22 \mu \mathrm{m})$ (Fig. $1 E, F)$ and colocalize with the proprioceptive marker NF200 (Fig. $1 H$ ) (Goldstein et al., 1991; Lawson et al., 1993). Consistent with this, LacZ staining fails to colocalize with the nociceptive marker CGRP (Fig. 1G) (Traub et al., 1990).

Based on the above results, Nf1SynIKO embryonic DRG cultures should only support the survival of TrkC-expressing neurons in the absence of neurotrophins. As expected, E13.5 DRG cultures from Nf1SynIKO mice yield increased numbers of surviving cells with a highly branched morphology, similar to that of 

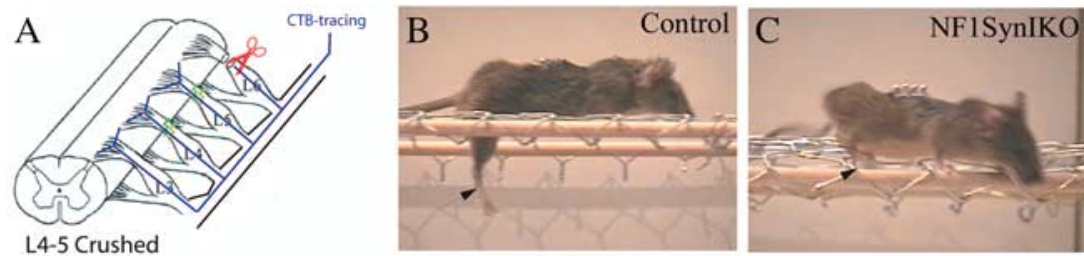

L4-5 Crushed
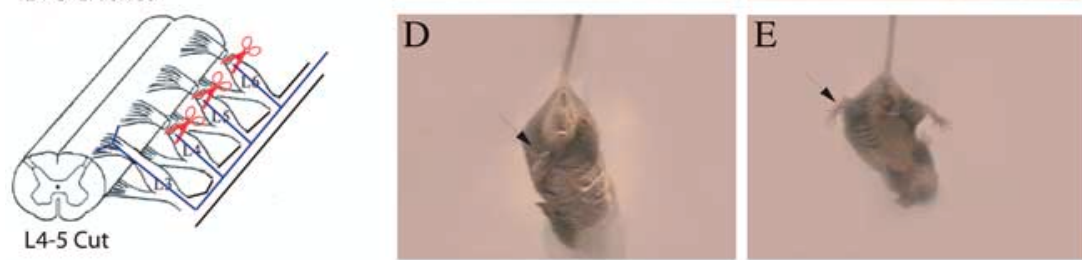

$\mathrm{F}$

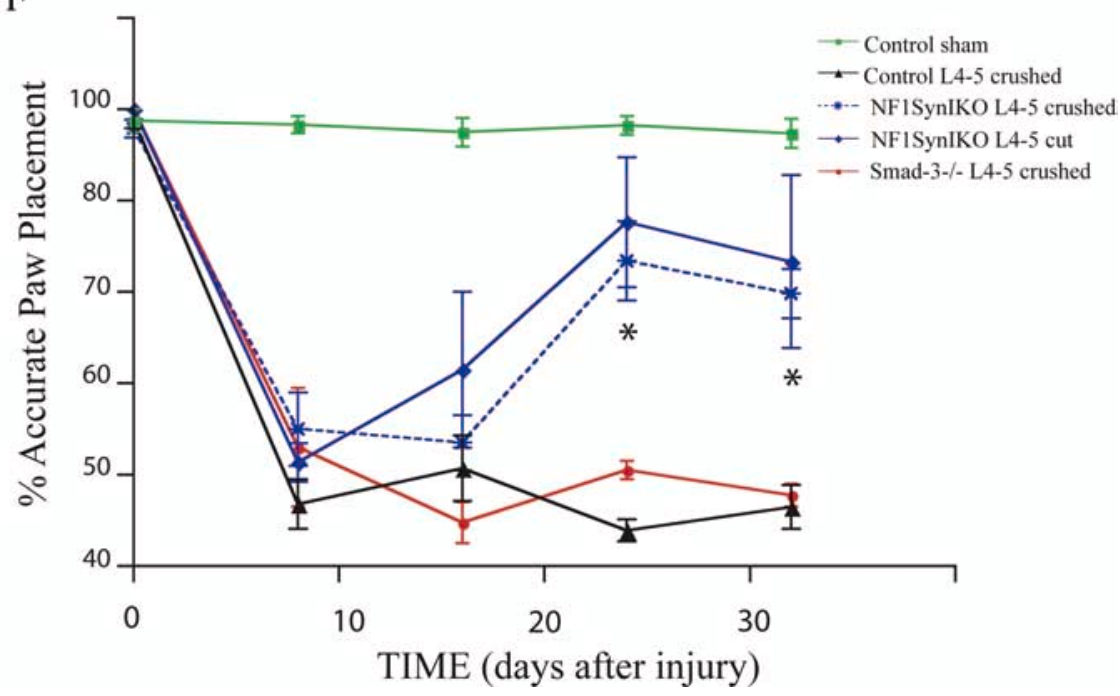

Figure 3. Spontaneous functional recovery of Nf1SynIKO mice after sensory denervation. $\boldsymbol{A}$, Diagrammatic representation of the injury paradigm. $\mathrm{L} 4-\mathrm{L} 5$ dorsal roots are either crushed or cut. Distinction between $\mathrm{L} 4-\mathrm{L} 5$ regeneration and collateral sprouting from $\mathrm{L} 3$ is achieved by transecting $\mathrm{L} 6$ in all animals. Labeling of proprioceptive axons is achieved by injection of the CTB tracer into the sciatic nerve. $\boldsymbol{B}-\boldsymbol{E}$, Compared with control mice $(\boldsymbol{B}, \boldsymbol{D})$, Nf7SynlKO mice spontaneously recover proprioceptive function $(\boldsymbol{C}$, $\boldsymbol{E})$, as indicated by regaining accurate locomotion in the grid assay, as well as deploying normal abductor responses. $\boldsymbol{F}$, Compared with normal sham controls $(n=4)$, paw placement accuracy is dramatically and permanently reduced after $L 4-\mathrm{L} 5$ crush injury in control animals $(n=7)$. In contrast, Nf1SynIKO conditional mutants recover capacity for precise paw placement after either crush $(59.60 \pm 5.42 \% ; n=5)$ or cut $(66.66 \pm 18.94 \% ; n=3) \mathrm{L} 4-\mathrm{L} 5$ injuries compared with permanent functional deficits in control mice (12.96 $\pm 4.77 \%)$ and Smad-3 knock-out mice $(9.50 \pm 4.50 \%)$ after crush injuries. ${ }^{*} p<0.001$, ANOVA with Fisher's test. Data represent mean \pm SEM.

control neurons treated with NT-3 (supplemental data 1, available at www.jneurosci.org as supplemental material). Together, our data indicate that DRG neurons undergoing Synapsin I-Cremediated $N f 1$ deletion primarily express TrkC and represent Ia afferents.

\section{Increased axonal growth and collateral branching in Nf1-/- neurons}

Unlike embryonic neurons, adult sensory neurons do not rely on neurotrophins for survival in culture. However, neurotrophins continue to stimulate their neurite outgrowth and sprouting (Hu-Tsai et al., 1994). To test whether ablation of Nf1 enhances the intrinsic capacity of neurite extension in vitro, axonal growth was evaluated in explant cultures from adult DRGs maintained for $48 \mathrm{~h}$ in the absence of neurotrophic support. Compared with controls (Fig. $2 A, B$ ), a subset of axons from $N$ f1SynIKO explants show increased axonal outgrowth (Fig. $2 C, D)$. Quantitative analysis of total axon length, visualized by phase-contrast microscopy and traced over several focal planes, showed a significant increase in axonal growth of adult $\mathrm{Nf1SynIKO}$ sensory neurons $(278.5 \pm 6.8 \mu \mathrm{m})$ compared with that of control mice $(235.6 \pm 6.6 \mu \mathrm{m} ; p \leq$ $0.0001)$. This result suggests that sensory neurons lacking $N f 1$ are endowed with an increased intrinsic capacity for neurite elongation.

Spontaneous proprioceptive recovery of Nf1SynIKO mice after dorsal rhizotomy The dorsal rhizotomy injury paradigm is well established for effects of CNS impediment to regeneration (Romero et al., 2001). Pain and proprioceptive information is relayed into the spinal cord via central dorsal root axonal projections from DRG neurons. Transected dorsal root afferents undergo spontaneous regeneration through the PNS compartment but abort their growth at the DREZ causing denervation of the dorsal spinal cord, and consequently resulting in permanent sensory-motor deficits (Carlstedt et al., 1987; Golding et al., 1999).

To evaluate whether the robust branching properties observed in culture for Nf1-deficient neurons might have effects on regenerative response of adult neurons in vivo, we tested the ability of Nf1SynIKO mice to recover from unilateral dorsal rhizotomy. This surgical procedure normally involves injuring the L3-L6 dorsal roots, which relay information from the hindlimb through the sciatic nerve. Whereas crush injury allows spontaneous regeneration within the PNS compartment, cut and ligated roots are prevented from regenerating (Romero et al., 2001). We compared control mice including $N f 1+/+$; SynI-Cre+ and Nf1flox/ flox genotypes $(n=22)$, to $N f 1$ SynIKO conditional mutants $(n=20)$ using the L4-L5 crush paradigm (Fig. 3A) (see Materials and Methods). Distinction between L4-L5 regeneration and collateral sprouting from L3 was achieved by transecting L6 in all animals together with either crush or cut L4-L5 surgeries. Thus, animals with L4-L6 transected roots have only L3 roots as primary afferents from the sciatic nerve. All mice undergoing unilateral L4-L6 rhizotomy exhibit immediate loss of limb function as assessed by behavioral analysis for nociception (plantar pinch test) and proprioception (Fig. 3B-F) (abductor reflex, grid walking, and paw print tests). However, in contrast to the permanent sensory loss observed in control animals, Nf1SynIKO mice show gradual recovery of proprioceptive function as early as 3 weeks after surgery, as indicated by grid walking (Fig. 3C) and abductor reflex analysis (Fig. 3E). Quantification of accurate paw placement during grid walking by slow motion video analysis, demonstrated significant functional deficits in all injured animals after dorsal 
rhizotomy during the first 2 weeks after injury (Fig. 3F; supplemental data 2, available at www.jneurosci.org as supplemental material). Thereafter, Nf1SynIKO mice begin to show recovery (Fig. $3 F$ ). To examine whether functional recovery could be attributable to an overcoming of CNS impediments at the DREZ (glial scar formation and myelin-mediated inhibition), a cohort of mice were subjected to L4-L5 sensory afferent transection and ligation (Fig. 3A). Surprisingly, the L4-L5 "cut and ligated" Nf1SynIKO mice also recover limb function (Fig. 3F; supplemental data 3, available at www.jneurosci.org as supplemental material). In contrast, all control mice exhibit permanent functional deficits (Fig. 3F; supplemental data 4, available at www.jneurosci.org as supplemental material).

Walking patterns assessed by paw print analysis (Fig. 4A) also showed permanent unilateral deficits in paw placement (claw foot) in all control injured animals, including Smad-3-/- mice (see below). In contrast, conditional $N f 1$ mutants regain normal foot placement after the third week after injury. Additional analysis of paw prints demonstrated significant reduction in toe spread index (the injured to noninjured ratio of the distance between the first and fifth toe) (Fig. $4 B$ ). This reduction is permanent in injured control animals. Conversely, Nf1 conditional mutants show significant improvement in toe spreading, evident in the third week after injury. To additionally control for possible nonspecific effects attributable to animal size, as well as to "blind" the surgeon to the genotype of the animal, we included Smad-3-/- animals in our study. Like Nf1SynIKO mice, Smad-3-/- mice are small (Zhu et al., 1998, 2001) and therefore visually indistinguishable. After dorsal rhizotomy, injured Smad-3-/- animals show permanent functional deficits similar to injured control mice (Figs. 3F, 4; supplemental data 5, available at www.jneurosci.org as supplemental material).

Despite the apparent recovery of proprioceptive function by the Nf1-deficient mutants, all injured animals show permanent nociceptive sensory loss, failing to respond to plantar pinch stimulation. The sum of these results indicate that Synapsin I-cremediated ablation of $\mathrm{Nf1}$ in neurons renders mice capable of functionally overcoming loss of L4-L5 afferent innervation but not through injured neuron recovery.

\section{Spared $N f 1-/-$ proprioceptive primary afferents sprout into the denervated spinal cord}

Visualization of the DREZ-reactive astrocytes in the lumbar spinal cord confirmed that, in contrast to sham injured controls, all mutant and control surgically injured mice (crushed, or cut and ligated) exhibit a typical gliotic scar that correlates with the absence of NF200-positive fibers penetrating through (supplemental data 6, available at www.jneurosci.org as supplemental material). Thus, permanent denervation occurs in all animals after dorsal rhizotomy, and injured $N f 1$-deficient neurons show no significant regenerative advantage after this type of injury.

In light of the spontaneous behavioral recovery of propriocep- tive function observed in injured NfISynIKO mice despite ligation of the injured afferents, we hypothesize that spared DRG collaterals are sprouting into the injured area and providing partial functional compensation. To examine whether $N f 1$ deletion induces spontaneous abnormal sprouting, double immunofluorescence was performed at different spinal cord levels of intact (uninjured) control and Nf1SynIKO mice. We combined tracttracing of proprioceptive primary afferents via transganglionic transport of the CTB label from the ipsilateral sciatic nerve, with visualization of nociceptive afferents by CGRP immunofluorescence (Rivero-Melian et al., 1992). Compared with controls (Fig. $5 A-C, G-I$ ), mice lacking neuronal $N f 1$ show no visible difference in the labeling of pain fibers by CGRP (Fig. $5 D-F$ ) or proprioceptive fibers by CTB (Fig. $5 J-L$ ) in the lumbar-sacral spinal cord. Both the staining intensity and afferent distribution are indistinguishable from the aged-matched normal controls. We conclude that loss of $\mathrm{Nf1}$ does not affect the normal development of sensory primary afferents from sensory neurons into the spinal cord.

We then evaluated pain and proprioceptive sensory innervation to the spinal cord in injured animals. Analysis of sagittal sections of the spinal cord at the L4-L5 dorsal root entry zone of control mice with either cut or crushed dorsal rhizotomies demonstrated that CTB-positive fibers are mostly absent from dorsal horn laminas III-V (Fig. 6A,B). In contrast, Nf1SynIKO conditional mutants with either type of injury demonstrate robust labeling of proprioceptive axons in deep dorsal horn laminas (Fig. $6 C, D)$. These results were confirmed by simultaneous visualization of CTB-labeled and CGRP-positive fibers in coronal sections of the spinal cord at the L4-L5 entry level (Fig. 6E-P). CTBlabeled proprioceptive fibers and CGRP-labeled nociceptive af- 

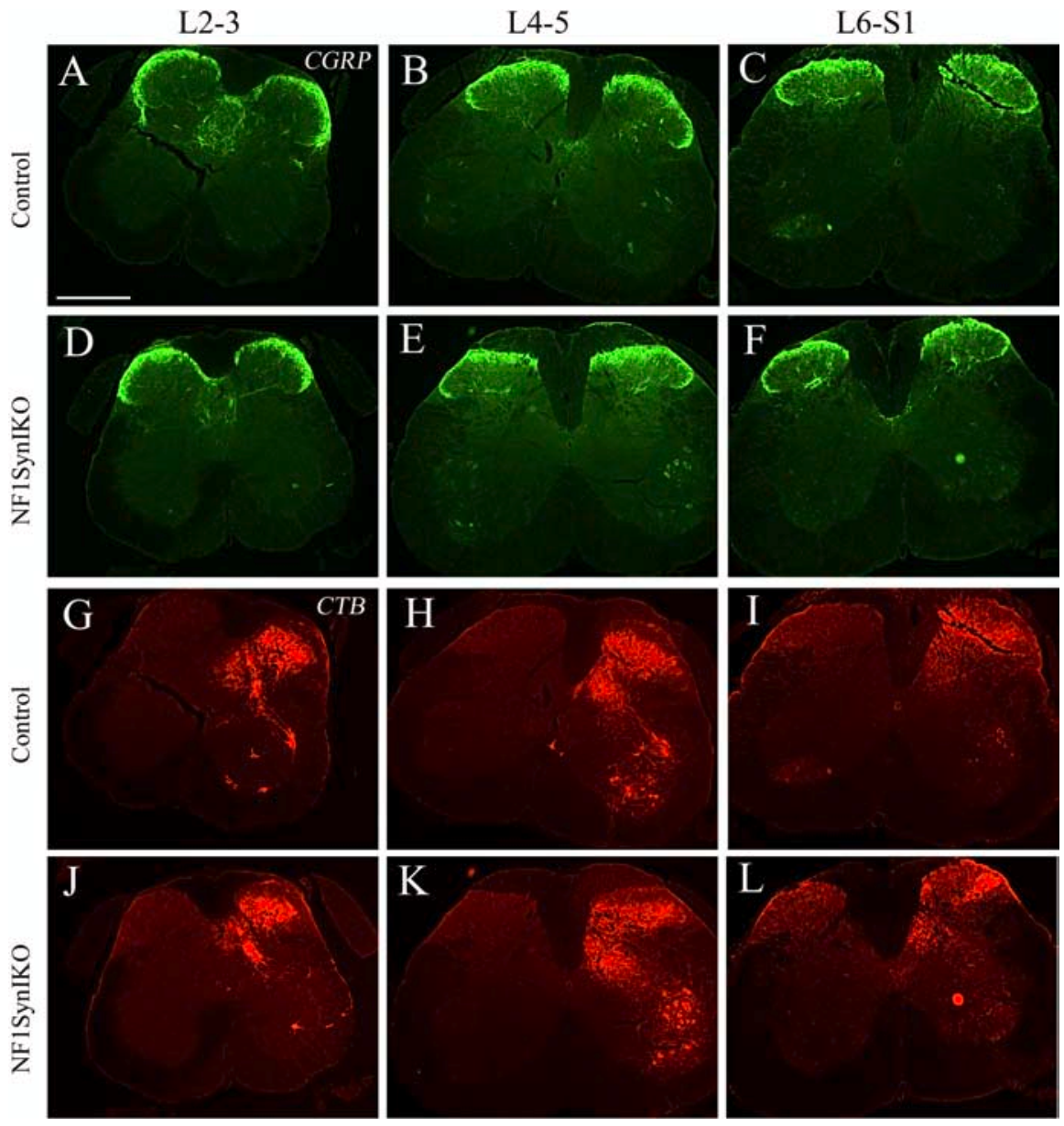

Figure 5. Normal nociceptive and proprioceptive afferents in uninjured Nf1SynIKO mice. $A-L$, Staining of proprioceptive $(C T B+$; red) and nociceptive (CGRP +; green) fibers in the lumbar-sacral spinal cord show that compared with controls ( $A-C$ $\mathbf{G}-\boldsymbol{I})$, CGRP innervation in lamina II, and CTB innervation in laminas III-V do not increase in uninjured Nf1SynlKO mice $(\boldsymbol{D}-\boldsymbol{F}, \boldsymbol{J}-\boldsymbol{L}$, respectively). Coronal sections are shown at different anterior-to-posterior lumbar-sacral spinal cord levels: lumbar 2-3 $(A, D, G$, J), lumbar 4-5 (B, E, $\boldsymbol{H}, \boldsymbol{K})$, and lumbar 6 -sacral $1(\boldsymbol{C}, \boldsymbol{F}, \boldsymbol{I}, \boldsymbol{L})$. (TB labeling of ventral motor neurons (lumbar 4-5) serves as positive control for tracing. Scale bar, $250 \mu \mathrm{m}$.

ferents occupy nonoverlapping target areas in laminas III-X, and lamina II, respectively (Fig. 6E,I,M). Compared with sham controls, both CTB and CGRP labeling of primary afferents are lost after crush injury in control animals (Fig. $6 F, J, N$ ). Conversely, $N f 1$ SynIKO mice with either crushed (Fig. $6 G, K, O$ ) or cut (Fig. $6 H, L, P)$ dorsal roots, show robust labeling of CTB-positive axons, and to a lesser extent of CGRP nociceptive fibers, throughout the lumbar spinal cord. The amount of CTB-positive fibers in the injured Nf1SynIKO mice is somewhat variable. However, compared with the absolute absence of Ia afferents in the injured control mice ( 0 of 4$)$, these fibers were unequivocally present in most of the $\mathrm{Nf1}-/$ - animals with crushed (4 of 5) and cut lesions (4 of 4), respectively. This difference is unlikely to be attributable to variable tract-tracing of these fibers, because positive CTB labeling of motor neurons in the ventral spinal cord is demonstrated for all animals (Fig. $6 A-D$, left inset; $E-H$, asterisks). The visualization of proprioceptive fibers in animals in which regeneration of the dorsal roots was prevented by the transection/ligation protocol rules out any possibility of functional recovery being mediated via L4-L5 DRGs. These data therefore indicate a greatly enhanced sprouting potential of uninjured (L3 sensory) neurons that lack $N f 1$ function in vivo.

\section{Contribution to sprouting activity by} the $N f 1-/-$ spinal cord

The increase in axonal branching observed after dorsal rhizotomy in Nf1SynIKO mice could be explained by the cell-autonomous capacity of Nf1-/- DRG neurons for collateral branching and neurite growth, as suggested by the increase axonal elongation of DRG sensory neurons in vitro (Fig. 2). However, because Synapsin I-Cre is also active in some neurons of the spinal cord (Zhu et al., 2001), it remains possible that absence of $N f 1$ in the denervated region could contribute in a paracrine manner to the compensatory sprouting by spared L3 afferents.

To address this possibility, we cocultured control or Nf1SynIKO DRGs together with control or Nf1SynIKO spinal cord explants (SC), and evaluated their growth response. Consistent with the culture studies (Fig. 2), Nf1-deficient sensory neurons exhibit enhanced intrinsic capacity for outgrowth (Fig. 7A,B). To avoid the potential bias of including well isolated axons as visualized by phase contrast microscopy, we specifically label proprioceptive neurons in the DRG explants by tracing a separate cohort of adult animals with CTB in the sciatic nerve, $4 \mathrm{~d}$ before harvesting L4-L5 DRGs. The prelabeled ganglia were then cocultured with either control or Nf1SynIKO SC and processed for the covisualization of CTB, CGRP, and the general axonal marker $\beta$-tubulin. Figure $7 C$ demonstrates the nonoverlapping labeling of proprioceptive and nociceptive neurons in all DRGs, evidencing the equal viability and efficient tract-tracing of the proprioceptive neurons. Axonal labeling by $\beta$-tubulin showed a qualitative increment in neurite growth from the Nf1SynIKO DRGs compared with control ganglia, whether cocultured with a normal or an $\mathrm{Nf1}-/-$ spinal cord (Fig. $7 C$ ). Quantitative analysis performed on CTB-positive neurites showed a threefold increase in axonal length of $N f 1$ SynIKO DRGs compared with DRGs from control animals, when cocultured with control SC (Fig. 7D). Moreover, when cultured with SC from $N f 1-/-$ conditional mutants, the Nf1SynIKO ganglia show a twofold enhancement in axonal length over that observed with the control SC. No significant effect of the Nf1SynIKO SC is observed on control DRGs (Fig. $7 C, D)$. This effect cannot be explained by a differential neuron survival in the cultured $N f 1-/-$ spinal cord slices, because propidium iodide labeling of dead cells was comparable with control slices (supplemental Fig. 7, available at www.jneurosci. org as supplemental material). These results demonstrate the increased capacity for axonal elongation in proprioceptive neurons from Nf1SynIKO mice, and indicate that $N f 1$ loss in the spinal cord may also contribute to the enhancement of in vivo spared nerve sprouting and thus to the spontaneous functional recovery of $N f 1$ SynIKO mice after dorsal rhizotomy. 
Control L4-5 cut

A

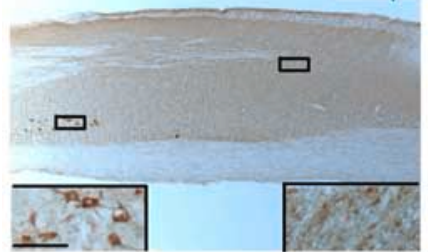

Control sham
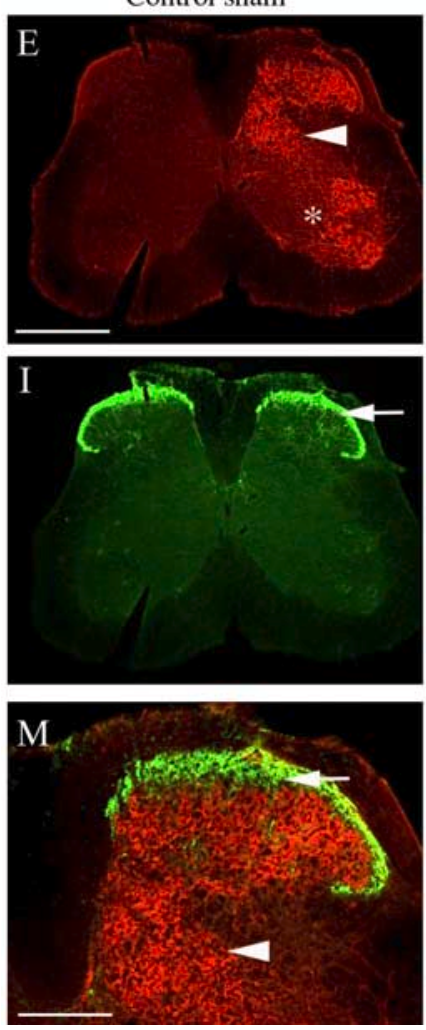

Control L4-5 crushed

B

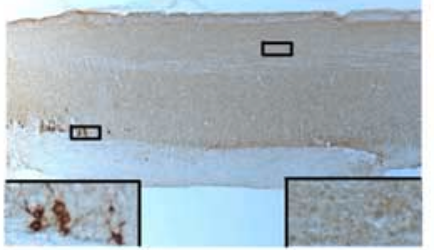

Control L4-5 crushed
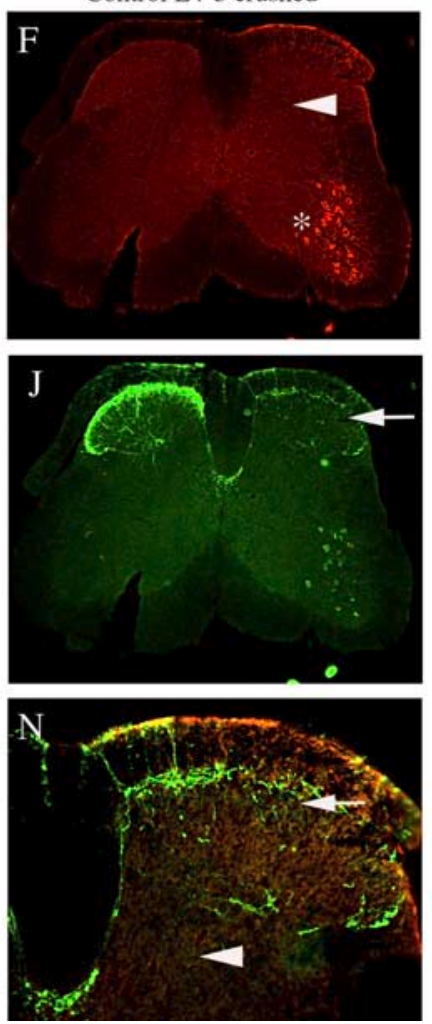

NF1SynIKO L4-5 crushed

C

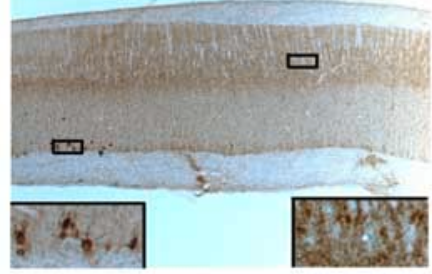

NF1SynIKO L4-5 crushed
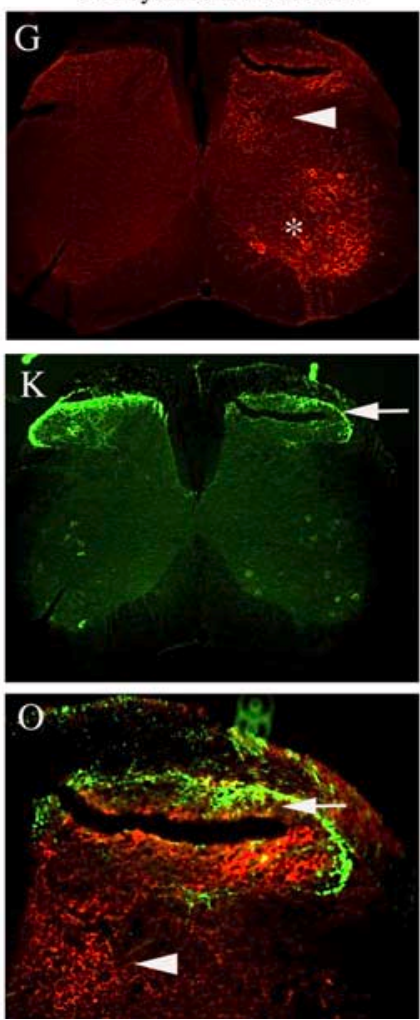

NF1SynIKO L4-5 cut

D

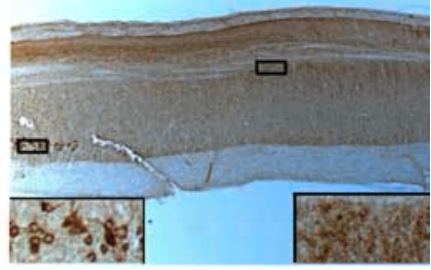

NF1SynIKO L4-5 cut
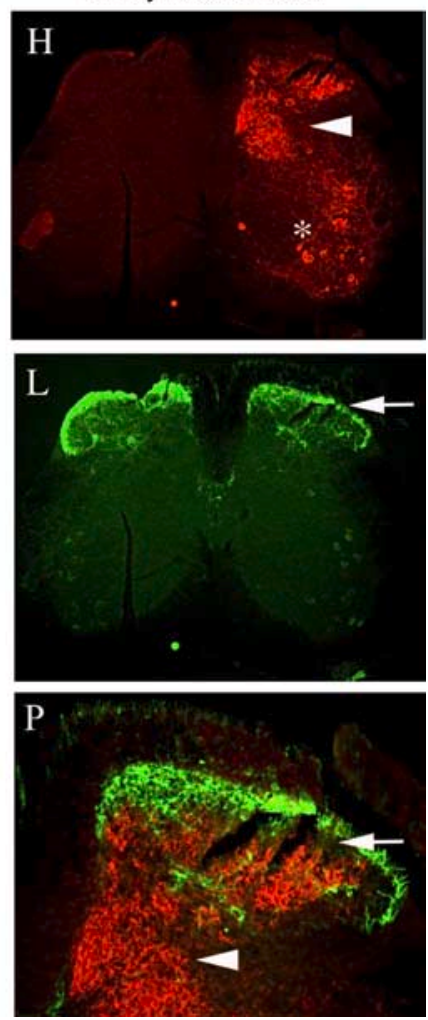

Figure 6. Nf1 deletion enhances axonal sprouting of spared proprioceptive primary afferents. $\boldsymbol{A}-\boldsymbol{D}$, Visualization of la fibers by CTB-tracing in parasagittal sections of the lumbar spinal cord, taken at approximately similar levels from the midline (see top corner inset in $A$ ). Control animals show a dramatic reduction of proprioceptive afferents in deep dorsal horn laminas after $L 4-L 5$ cut or crush rhizotomy $(\boldsymbol{A}$, $\boldsymbol{B}$, right insets), despite efficient tracing of the ventral motor neurons (left insets). In contrast, robust CTB labeling is observed in Nf1SynIK0 mice with either crushed ( $\boldsymbol{C}$ or cut-ligated (D) $L 4-L 5$ injuries. $\boldsymbol{E}-\boldsymbol{P}$, Double immunofluorescence of proprioceptive (CTB+; red) and nociceptive (CGRP+; green) fibers in the dorsal spinal cord at L4 -L5 DREZ level shows that, compared with sham controls (E, $\boldsymbol{I}, \boldsymbol{M})$ ), CGRP innervation in lamina II (arrows) is reduced in all injured animals $(\boldsymbol{J}, \boldsymbol{K}, \boldsymbol{L})$. However, (TB innervation in laminas III-V (arrowheads), lost after crush injury in control animals $(\boldsymbol{F}, \boldsymbol{N})$, is evident in the dorsal horn of Nf1SynIK0 mice with either crush $(G, 0)$ or cut injuries $(\boldsymbol{H}, \boldsymbol{P})$, indicating the sprouting of $L 3$ afferents into $L 4-L 5$ ventral motor neurons. Scale bars: $A$, inset, $60 \mu \mathrm{m} ; \boldsymbol{E}, 250 \mu \mathrm{m} ; \boldsymbol{M}, 100 \mu \mathrm{m}$.

\section{Molecular correlates in $\mathrm{Nf1}-/-$ neurons}

To investigate the molecular mechanism underlying the enhanced intrinsic growth capacity for growth in the Nf1-/-DRG neurons, we sought to evaluate the status of Ras-dependent pathways. In agreement with our previous report (Zhu et al., 2001), we found elevated levels of activated extracellular signal-regulated kinase 1/2 (phospho-ERK1/2) (a subtype of MAPK) in the Nf1SynIKO cerebral cortex, cerebellum, and spinal cord. In addition, we observed a twofold increase of pERK1/2 levels in Nf1-/- DRGs compared with control littermates (Fig. 8). These data corroborate our previous observations in the Nf1SynIKO CNS, and extend that to DRGs, demonstrating the constitutive activation of the Raf-MEK-MAPK signaling pathway in the Nf1SynIKO PNS.

The phosphatidyl inositol 3-kinase (PI3K)-Akt-glycogen synthase kinase $3 \beta$ (GSK3 $\beta$ ) cascade has also been associated with neurotrophin-induced survival and neurite outgrowth (Zhou et al., 2004). In contrast to the changes observed with
pERK1/2 in CNS, the phosphorylation and activation state of Akt and inactive state of GSK $3 \beta$ in different $N f 1$ SynIKO CNS regions are comparable with those of controls (Fig. 8). In adult $\mathrm{Nf1-/-}$ DRGs, however, phospho-Akt levels appears to increase and phospho-GSK $3 \beta$ levels appears to decrease compared with controls (Fig. 8), although these values do not reach statistical significance. Together, these data demonstrate a differential activation of Ras-effector cascades in response to $N f 1$ deletion in CNS and PNS neurons, and reveal a possible constitutively coactivation of both the Raf-MEK-MAPK and the PI3K-Akt-GSK3 $\beta$ cascades in Ras-deregulated $N f 1-/-$ adult DRG neurons.

\section{Discussion}

Deletion of $N f 1$ in neurons results in enhanced collateral sprouting

Neurotrophic factors regulate neuronal survival and morphological differentiation through Trk receptors. In the CNS, NT-3 has 
A

WT DRG
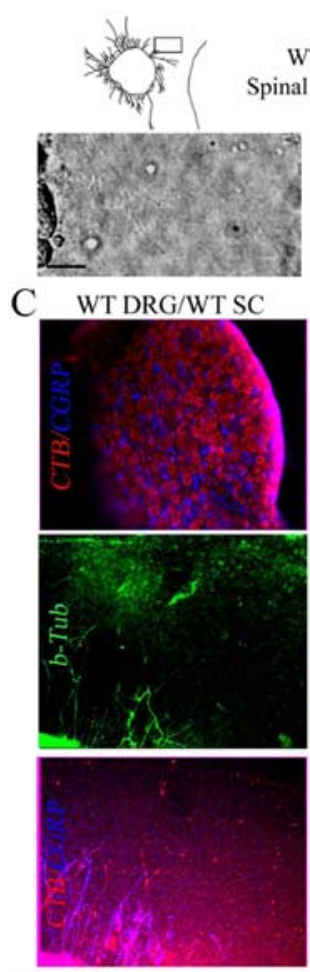

D

\begin{tabular}{|l|l|l|l|}
\hline $73.9 \pm 6.6 \mu \mathrm{m}$ & $178.9 \pm 19.5 \mu \mathrm{m}$ & $76.3 \pm 14.7 \mu \mathrm{m}$ & $335.4 \pm 57.1 \mu \mathrm{m} *$ \\
\hline
\end{tabular}

Figure 7. Nf1SynIKO spinal cord enhances axon growth from Nf1SynIKO DRGs. $\boldsymbol{A}, \boldsymbol{B}$, Coculture of control and Nf1SynIKO DRG explants with control $(\boldsymbol{A})$ or Nf1SynIKO SC $(\boldsymbol{B})$ shows increased neurite growth of the Nf1SynIKO explants compared with control DRGS. C, Triple immunofluorescence analysis demonstrates the nonoverlapping labeling of proprioceptive and nociceptive neurons in all DRGs (CTB, red; CGRP, blue; $\beta$-tubulin, green) and a qualitative increase in axonal growth of $N f 1-/-$ ganglia. $D$, Quantitative analysis of CTB-positive neurites shows a twofold increase in axonal length of Nf1SynIKO DRGs when cocultured with control SC. Moreover, when cultured with SC from Nf1 - / - conditional mutants, the Nf1SynIKO ganglia show a fourfold increase in axonal length over that of WT DRG/WT SC cultures, demonstrating the synergistic effect of the Nf1 - I - SC on the Nf1SynIKO DRGs. Tracings of whole DRG explants and micrographs of axons in each explant are shown according to their actual placing in relation to the SC slices. The squares indicate the photographed area. Scale bar, $50 \mu \mathrm{m} .{ }^{*} p<0.01$, KO DRG/WT SC versus KO DRG/KO SC, ANOVA Newman-Keuls multiple comparisons. Data represent mean \pm SEM of $6-38$ axons per treatment group.

been specifically implicated in functions related to axonal growth and arborization in target fields (Ma et al., 2002; Patel et al., 2003), as well as in sprouting after injury. Trk receptor-mediated axon extension and target innervation induced by neurotrophins results from activation of their downstream effectors including Ras, PI3K/Akt, MEK/ERK, and phospholipase C $\gamma$ (Atwal et al., 2000; Huang and Reichardt, 2001; Markus et al., 2002a). Neurofibromin, the protein encoded by NF1, serves as a checkpoint for Ras-mediated signaling downstream of Trk family receptors (Klesse and Parada, 1998; Klesse et al., 1999).

In this report, we demonstrate that ablation of $N f 1$ in adult proprioceptive sensory DRG neurons endows these cells with enhanced in vitro capacity for axonal growth and collateral branching.

\section{Functional recovery}

We extended the primary culture studies to a classic in vivo model for nerve injury and repulsion by CNS, the dorsal rhizotomy (Carlstedt et al., 1987; Goldstein et al., 1991). In contrast to the permanent sensory deficits described in the literature and observed in control mice after dorsal rhizotomy, over the course of several weeks $N f 1$ SynIKO mice progressively recover propriocep- tive function. This remarkable spontaneous recovery is observed in the Nf1 conditional mutant mice, despite surgical resection and ligation. Therefore, such robust recovery cannot be attributable to an inadequate or inconsistent injury technique, and is likely achieved through compensatory collateral sprouting of spared adjacent sensory afferents. Consistent with this view, the mutant mice show no significant changes in astrocytic scar formation at the DREZ and no evidence of regeneration from the damaged DRG afferents (supplemental data 6, available at www.jneurosci.org as supplemental material), suggesting that the environment remains unfavorable for regeneration in the mutant cord.

The ability of DRG neurons to sprout after injury is well documented for pain and mechanoceptor fibers (McMahon and Kett-White, 1991; LaMotte and Kapadia, 1993), whereas nonpeptidergic (IB-4 positive) and muscle proprioceptive afferents have limited capacity for collateral branching (Belyantseva and Lewin, 1999). This limited sprouting capacity is insufficient to mediate functional recovery after dorsal rhizotomy in normal animals. In the context of $N f 1$ loss, the capacity of neighboring spared proprioceptive sensory neurons to invade the damaged area by sprouting is enhanced to a sufficient degree that in all cases partial functional recovery could be monitored. Functional collateralization of the Nf1SynIKO L3 DRGs into the L4-L5 denervated motor neurons for proprioceptive control seems feasible because these neurons are known to project through the sciatic nerve in mice (Forsberg et al., 1996), and although the precise mechanism by which L3 DRG Nf1-/- neurons control muscle targets in the hindlimb is unknown, it is not unlikely that these neurons also sprout peripherally (Sanapanich et al., 2002).

\section{Paracrine effects}

Interestingly, we did not observe spurious enhanced neuronal sprouting in spinal cords of uninjured Nf1SynIKO mice. Thus, apparently after experimental injury $N f 1-/-$ neurons have an enhanced capacity to sense and respond to spinal cord denervation, suggesting a role for the target environment. Because neurons in the spinal cord of $N f 1$ SynIKO mice also lack $N f 1$, we considered whether paracrine effects from these Nf1-deficient neurons might also contribute to the observed in vivo functional recovery. To test this possibility, we developed a novel experimental protocol for the unequivocal visualization of adult proprioceptive neurites in vitro. The results from coculturing of spinal cord explants with prelabeled proprioceptive DRG neurons indicate an enhanced axonal outgrowth activity in mutant spinal cord cocultures. Therefore, the increased axonal elongation observed in $\mathrm{Nf1}-/-$ TrkC neurons reflects not only an improved intrinsic capacity for neurite growth but also an enhanced response of these neurons to local growth cues from the denervated 
spinal cord. This is in agreement with the "growth factor hypersensitivity" that $N f 1-/-$ and $N f 1+/-$ cells exhibit to certain paracrine factors such as neurotrophins, CSF-1 (colony-stimulating factor 1 ), and Kit ligand in other cellular contexts that relate to $\mathrm{Nf1}$-associated pathology (Vogel et al., 1995; Largaespada et al., 1996; Yang et al., 2003; Le et al., 2004). Identification of the factor(s) responsible for this activity may have usefulness in future development of nerve regeneration therapies. Together, our results suggest combined cell autonomous (DRG axonal elongation) and non-cell-autonomous (denervated spinal cord) effects, as likely cellular mechanisms underlying the spontaneous recovery of proprioception in rhizotomized $N f 1-/-$ mice. However, separate deletion of $N f 1$ in the DRGs, and in the spinal cord, are needed to confirm this notion.

\section{Molecular mechanism}

Sensory neurons respond to neurotrophins for cell survival and axonal growth primarily through the activation of the PI3K-Akt-GSK3 $\beta$ and Raf-MEK-ERK, Ras signaling pathways that are negatively regulated by neurofibromin (Atwal et al., 2000; Vogel et al., 2000; Zhou et al., 2004). Whereas most evidence points to the critical role for the Ras-PI3K effectors as mediators of cell survival in both wild-type (WT) and Nf1-/- DRG neurons (Klesse and Parada, 1998), the molecular mechanism underlying cytoskeletal reorganization during neurotrophin-induced axonal growth and collateral branching is less clearly defined. In embryonic DRG neurons, NGF elicits axonal growth through PI3K phosphorylation and GSK3 $\beta$ inactivation, and proceeds despite ERK signaling blockade, suggesting a necessary and sufficient role for the PI3K-Akt-GSK3 $\beta$ cascade in neurite growth (Jones et al., 2003; Zhou et al., 2004). However, when neurotrophin-induced axonal growth is studied independently from cell survival in embryonic sensory neurons, neurite extension is blocked by either MEK or PI3K inhibitors (Atwal et al., 2000), and specific activation of either the Raf-MEK-ERK or the PI3K-Akt-GSK3 $\beta$ cascade in Bax- / - embryonic DRG neurons, selectively induces axonal elongation, and distal branching, respectively (Markus et al., 2002a). Our results indicate that both the Raf-MEK-ERK and the PI3K-Akt-GSK3 $\beta$ Ras effectors are likely constitutively activated in adult $N f 1$ SynIKO DRG neurons, suggesting that both Ras-effector cascades may underlie the increased capacity on $\mathrm{Nf1}-/$ - neurons for collateral sprouting.

The precise mechanisms, by which activation of the Raf and the PI3K pathways might coordinate the assembly of microtubules for axonal sprouting in response to injury, remain to be fully elucidated. Transcription factors elicited by injury such as c-Jun, ATF3 (activating transcription factor 3), CREB (cAMP response element-binding protein), and STATs (signal transducers and activators of transcription), are likely candidates down- stream of Erk activation (Sheu et al., 2000; Pearson et al., 2003). Alternatively, effector molecules downstream of neurofibromin might also be involved, because activation of Ras signaling, either by expression of a constitutively activated form (Genot et al., 1996) or by Nf1 deletion (Gitler et al., 2003), is known to activate the transcription factor nuclear factor of activated $\mathrm{T}$ cells $\mathrm{cl}$ (NFATc1) in endothelial cells. Furthermore, calcineurin/NFAT activation is critically involved in elongation and arborizing growth of sensory neurons (Graef et al., 2003).

Our data are most consistent with a scenario in which the elevated Raf/PI3K activity in Nf1-/- neurons endow these cells with increased intrinsic capacity for growth, and render them hypersensitive to stimulation by extracellular signals, such as those likely to emanate from the denervated spinal cord.

\section{Significance for neural trauma and regeneration}

Current studies on nerve regeneration after injury focus most attention on understanding and neutralizing the unfavorable environment created by inhibitory myelin components, extracellular matrix and glial scar (Fournier et al., 2003; Fouad et al., 2005). Yet, clearly mature neurons have reduced intrinsic capacity for growth and sprouting compared with embryonic neurons. Thus, 
identifying cell-autonomous mechanisms that enhance adult neuron collateral branching remains an important and understudied area of research (Homma et al., 2003; Rico et al., 2004).

For the present studies, we selected DRG neurons (in vivo and cultured) as physiologically relevant model substrates for spinal cord injury. Cultured DRG neurons are routinely used in the nerve regeneration field for studies to examine the inhibitory qualities of myelin components such as NOGO (Chen et al., 2000; GrandPre et al., 2000), MAG (myelin-associated glycoprotein) (McKerracher et al., 1994), and OMgp (oligodendrocyte myelin glycoprotein) (Wang et al., 2002). For spinal cord and DRG explant studies, we worked with adult tissue despite its known reduced capacity for axonal growth in culture compared with embryonic neurons. Indeed, classic studies on the molecular mechanisms underlying embryonic axonal growth and collateral branching exploited the natural enhanced capacity of embryonic tissues to exhibit these properties (Zhang et al., 1994; Wang et al., 1999; Homma et al., 2003). However, we felt that studying adult tissue more closely resembled physiological conditions surrounding injury. Despite these difficulties, adult DRG explants revealed an increased growth response in the absence of $\mathrm{Nf1}$.

In summary, the present study indicates that $N f 1$ deletion in sensory primary afferents conveys these cells with an enhanced capacity for functional collateral sprouting in response to spinal cord denervation injury. These results underline neurofibromin as a useful therapeutic target to increase the sprouting capacity of spared neurons after neural trauma.

\section{References}

Adamchik Y, Frantseva MV, Weisspapir M, Carlen PL, Perez Velazquez JL (2000) Methods to induce primary and secondary traumatic damage in organotypic hippocampal slice cultures. Brain Res Brain Res Protoc 5:153-158.

Atwal JK, Massie B, Miller FD, Kaplan DR (2000) The TrkB-Shc site signals neuronal survival and local axon growth via MEK and P13-kinase. Neuron 27:265-277.

Averill S, McMahon SB, Clary DO, Reichardt LF, Priestley JV (1995) Immunocytochemical localization of trkA receptors in chemically identified subgroups of adult rat sensory neurons. Eur J Neurosci 7:1484-1494.

Belyantseva IA, Lewin GR (1999) Stability and plasticity of primary afferent projections following nerve regeneration and central degeneration. Eur J Neurosci 11:457-468.

Bomze HM, Bulsara KR, Iskandar BJ, Caroni P, Skene JH (2001) Spinal axon regeneration evoked by replacing two growth cone proteins in adult neurons. Nat Neurosci 4:38-43.

Bradbury EJ, Moon LD, Popat RJ, King VR, Bennett GS, Patel PN, Fawcett JW, McMahon SB (2002) Chondroitinase ABC promotes functional recovery after spinal cord injury. Nature 416:636-640.

Cai D, Shen Y, De Bellard M, Tang S, Filbin MT (1999) Prior exposure to neurotrophins blocks inhibition of axonal regeneration by MAG and myelin via a cAMP-dependent mechanism. Neuron 22:89-101.

Carlstedt T, Dalsgaard CJ, Molander C (1987) Regrowth of lesioned dorsal root nerve fibers into the spinal cord of neonatal rats. Neurosci Lett 74:14-18.

Chen MS, Huber AB, van der Haar ME, Frank M, Schnell L, Spillmann AA, Christ F, Schwab ME (2000) Nogo-A is a myelin-associated neurite outgrowth inhibitor and an antigen for monoclonal antibody IN-1. Nature 403:434-439.

Forsberg E, Hirsch E, Frohlich L, Meyer M, Ekblom P, Aszodi A, Werner S, Fassler R (1996) Skin wounds and severed nerves heal normally in mice lacking tenascin-C. Proc Natl Acad Sci USA 93:6594-6599.

Fouad K, Schnell L, Bunge MB, Schwab ME, Liebscher T, Pearse DD (2005) Combining Schwann cell bridges and olfactory-ensheathing glia grafts with chondroitinase promotes locomotor recovery after complete transection of the spinal cord. J Neurosci 25:1169-1178.

Fournier AE, Takizawa BT, Strittmatter SM (2003) Rho kinase inhibition enhances axonal regeneration in the injured CNS. J Neurosci 23:1416-1423.
Genot E, Cleverley S, Henning S, Cantrell D (1996) Multiple p21 ras effector pathways regulate nuclear factor of activated $\mathrm{T}$ cells. EMBO J 15:3923-3933.

Gitler AD, Zhu Y, Ismat FA, Lu MM, Yamauchi Y, Parada LF, Epstein JA (2003) Nf1 has an essential role in endothelial cells. Nat Genet 33:75-79.

Golding JP, Bird C, McMahon S, Cohen J (1999) Behaviour of DRG sensory neurites at the intact and injured adult rat dorsal root entry zone: postnatal neurites become paralysed, whilst injury improves the growth of embryonic neurites. Glia 26:309-323.

Goldstein ME, House SB, Gainer H (1991) NF-L and peripherin immunoreactivities define distinct classes of rat sensory ganglion cells. J Neurosci Res 30:92-104.

Graef IA, Wang F, Charron F, Chen L, Neilson J, Tessier-Lavigne M, Crabtree GR (2003) Neurotrophins and netrins require calcineurin/NFAT signaling to stimulate outgrowth of embryonic axons. Cell 113:657-670.

GrandPre T, Nakamura F, Vartanian T, Strittmatter SM (2000) Identification of the Nogo inhibitor of axon regeneration as a Reticulon protein. Nature 403:439-444.

GrandPre T, Li S, Strittmatter SM (2002) Nogo-66 receptor antagonist peptide promotes axonal regeneration. Nature 417:547-551.

Homma N, Takei Y, Tanaka Y, Nakata T, Terada S, Kikkawa M, Noda Y, Hirokawa N (2003) Kinesin superfamily protein 2A (KIF2A) functions in suppression of collateral branch extension. Cell 114:229-239.

Horner PJ, Gage FH (2000) Regenerating the damaged central nervous system. Nature 407:963-970.

Huang EJ, Reichardt LF (2001) Neurotrophins: roles in neuronal development and function. Annu Rev Neurosci 24:677-736.

Hu-Tsai M, Winter J, Emson PC, Woolf CJ (1994) Neurite outgrowth and GAP-43 mRNA expression in cultured adult rat dorsal root ganglion neurons: effects of NGF or prior peripheral axotomy. J Neurosci Res 39:634-645.

Jones DM, Tucker BA, Rahimtula M, Mearow KM (2003) The synergistic effects of NGF and IGF-1 on neurite growth in adult sensory neurons: convergence on the PI 3-kinase signaling pathway. J Neurochem 86:1116-1128.

Klesse LJ, Parada LF (1998) p21 ras and phosphatidylinositol-3 kinase are required for survival of wild-type and NF1 mutant sensory neurons. J Neurosci 18:10420-10428.

Klesse LJ, Meyers KA, Marshall CJ, Parada LF (1999) Nerve growth factor induces survival and differentiation through two distinct signaling cascades in PC12 cells. Oncogene 18:2055-2068.

Krassioukov AV, Ackery A, Schwartz G, Adamchik Y, Liu Y, Fehlings MG (2002) An in vitro model of neurotrauma in organotypic spinal cord cultures from adult mice. Brain Res Brain Res Protoc 10:60-68.

LaMotte CC, Kapadia SE (1993) Deafferentation-induced terminal field expansion of myelinated saphenous afferents in the adult rat dorsal horn and the nucleus gracilis following pronase injection of the sciatic nerve. J Comp Neurol 330:83-94.

Largaespada DA, Brannan CI, Jenkins NA, Copeland NG (1996) Nf1 deficiency causes Ras-mediated granulocyte/macrophage colony stimulating factor hypersensitivity and chronic myeloid leukaemia. Nat Genet 12:137-143.

Lawson SN, Perry MJ, Prabhakar E, McCarthy PW (1993) Primary sensory neurones: neurofilament, neuropeptides, and conduction velocity. Brain Res Bull 30:239-243.

Le DT, Kong N, Zhu Y, Lauchle JO, Aiyigari A, Braun BS, Wang E, Kogan SC, Le Beau MM, Parada L, Shannon KM (2004) Somatic inactivation of $\mathrm{Nf1}$ in hematopoietic cells results in a progressive myeloproliferative disorder. Blood 103:4243-4250.

Lentz SI, Knudson CM, Korsmeyer SJ, Snider WD (1999) Neurotrophins support the development of diverse sensory axon morphologies. J Neurosci 19:1038-1048.

Liebl DJ, Tessarollo L, Palko ME, Parada LF (1997) Absence of sensory neurons before target innervation in brain-derived neurotrophic factor-, neurotrophin 3-, and TrkC-deficient embryonic mice. J Neurosci 17:9113-9121.

Lu P, Yang H, Jones LL, Filbin MT, Tuszynski MH (2004) Combinatorial therapy with neurotrophins and cAMP promotes axonal regeneration beyond sites of spinal cord injury. J Neurosci 24:6402-6409.

Ma L, Harada T, Harada C, Romero M, Hebert JM, McConnell SK, Parada LF (2002) Neurotrophin-3 is required for appropriate establishment of thalamocortical connections. Neuron 36:623-634. 
Markus A, Zhong J, Snider WD (2002a) Raf and akt mediate distinct aspects of sensory axon growth. Neuron 35:65-76.

Markus A, Patel TD, Snider WD (2002b) Neurotrophic factors and axonal growth. Curr Opin Neurobiol 12:523-531.

McDonald JW, Liu XZ, Qu Y, Liu S, Mickey SK, Turetsky D, Gottlieb DI, Choi DW (1999) Transplanted embryonic stem cells survive, differentiate and promote recovery in injured rat spinal cord. Nat Med 5:1410-1412.

McKerracher L, David S, Jackson DL, Kottis V, Dunn RJ, Braun PE (1994) Identification of myelin-associated glycoprotein as a major myelinderived inhibitor of neurite growth. Neuron 13:805-811.

McMahon SB, Kett-White R (1991) Sprouting of peripherally regenerating primary sensory neurones in the adult central nervous system. J Comp Neurol 304:307-315.

Merkler D, Metz GA, Raineteau O, Dietz V, Schwab ME, Fouad K (2001) Locomotor recovery in spinal cord-injured rats treated with an antibody neutralizing the myelin-associated neurite growth inhibitor Nogo-A. J Neurosci 21:3665-3673.

Molliver DC, Radeke MJ, Feinstein SC, Snider WD (1995) Presence or absence of TrkA protein distinguishes subsets of small sensory neurons with unique cytochemical characteristics and dorsal horn projections. J Comp Neurol 361:404-416.

Morgenstern DA, Asher RA, Fawcett JW (2002) Chondroitin sulphate proteoglycans in the CNS injury response. Prog Brain Res 137:313-332.

Neumann S, WoolfCJ (1999) Regeneration of dorsal column fibers into and beyond the lesion site following adult spinal cord injury. Neuron 23:83-91.

Neumann S, Bradke F, Tessier-Lavigne M, Basbaum AI (2002) Regeneration of sensory axons within the injured spinal cord induced by intraganglionic cAMP elevation. Neuron 34:885-893.

Patel TD, Kramer I, Kucera J, Niederkofler V, Jessell TM, Arber S, Snider WD (2003) Peripheral NT3 signaling is required for ETS protein expression and central patterning of proprioceptive sensory afferents. Neuron 38:403-416.

Pearse DD, Pereira FC, Marcillo AE, Bates ML, Berrocal YA, Filbin MT, Bunge MB (2004) cAMP and Schwann cells promote axonal growth and functional recovery after spinal cord injury. Nat Med 10:610-616.

Pearson AG, Gray CW, Pearson JF, Greenwood JM, During MJ, Dragunow M (2003) ATF3 enhances c-Jun-mediated neurite sprouting. Brain Res Mol Brain Res 120:38-45.

Qiu J, Cai D, Dai H, McAtee M, Hoffman PN, Bregman BS, Filbin MT (2002) Spinal axon regeneration induced by elevation of cyclic AMP. Neuron 34:895-903.

Ramer MS, Priestley JV, McMahon SB (2000) Functional regeneration of sensory axons into the adult spinal cord. Nature 403:312-316.

Rico B, Beggs HE, Schahin-Reed D, Kimes N, Schmidt A, Reichardt LF (2004) Control of axonal branching and synapse formation by focal adhesion kinase. Nat Neurosci 7:1059-1069.

Rivero-Melian C, Rosario C, Grant G (1992) Demonstration of transganglionically transported choleragenoid in rat spinal cord by immunofluorescence cytochemistry. Neurosci Lett 145:114-117.

Romero MI, Rangappa N, Garry MG, Smith GM (2001) Functional regeneration of chronically injured sensory afferents into adult spinal cord after neurotrophin gene therapy. J Neurosci 21:8408-8416.
Sanapanich K, Morrison WA, Messina A (2002) Physiologic and morphologic aspects of nerve regeneration after end-to-end or end-to-side coaptation in a rat model of brachial plexus injury. J Hand Surg [Am] 27:133-142.

Schwab ME (2002) Repairing the injured spinal cord. Science 295:1029-1031.

Sheu JY, Kulhanek DJ, Eckenstein FP (2000) Differential patterns of ERK and STAT3 phosphorylation after sciatic nerve transection in the rat. Exp Neurol 166:392-402.

Soriano P (1999) Generalized lacZ expression with the ROSA26 Cre reporter strain. Nat Genet 21:70-71.

Takami T, Oudega M, Bates ML, Wood PM, Kleitman N, Bunge MB (2002) Schwann cell but not olfactory ensheathing glia transplants improve hindlimb locomotor performance in the moderately contused adult rat thoracic spinal cord. J Neurosci 22:6670-6681.

Teng YD, Lavik EB, Qu X, Park KI, Ourednik J, Zurakowski D, Langer R, Snyder EY (2002) Functional recovery following traumatic spinal cord injury mediated by a unique polymer scaffold seeded with neural stem cells. Proc Natl Acad Sci USA 99:3024-3029.

Traub RJ, Allen B, Humphrey E, Ruda MA (1990) Analysis of calcitonin gene-related peptide-like immunoreactivity in the cat dorsal spinal cord and dorsal root ganglia provide evidence for a multisegmental projection of nociceptive C-fiber primary afferents. J Comp Neurol 302:562-574.

Vogel KS, Brannan CI, Jenkins NA, Copeland NG, Parada LF (1995) Loss of neurofibromin results in neurotrophin-independent survival of embryonic sensory and sympathetic neurons. Cell 82:733-742.

Vogel KS, El-Afandi M, Parada LF (2000) Neurofibromin negatively regulates neurotrophin signaling through p21ras in embryonic sensory neurons. Mol Cell Neurosci 15:398-407.

Wang KC, Koprivica V, Kim JA, Sivasankaran R, Guo Y, Neve RL, He Z (2002) Oligodendrocyte-myelin glycoprotein is a Nogo receptor ligand that inhibits neurite outgrowth. Nature 417:941-944.

Wang KH, Brose K, Arnott D, Kidd T, Goodman CS, Henzel W, TessierLavigne M (1999) Biochemical purification of a mammalian slit protein as a positive regulator of sensory axon elongation and branching Cell 96:771-784.

Yang FC, Ingram DA, Chen S, Hingtgen CM, Ratner N, Monk KR, Clegg T, White H, Mead L, Wenning MJ, Williams DA, Kapur R, Atkinson SJ, Clapp DW (2003) Neurofibromin-deficient Schwann cells secrete a potent migratory stimulus for $\mathrm{Nf} 1+/-$ mast cells. J Clin Invest 112:1851-1861.

Zhang L, Schmidt RE, Yan Q, Snider WD (1994) NGF and NT-3 have differing effects on the growth of dorsal root axons in developing mammalian spinal cord. J Neurosci 14:5187-5201.

Zhou FQ, Zhou J, Dedhar S, Wu YH, Snider WD (2004) NGF-induced axon growth is mediated by localized inactivation of GSK-3beta and functions of the microtubule plus end binding protein APC. Neuron 42:897-912.

Zhu Y, Richardson JA, Parada LF, Graff JM (1998) Smad3 mutant mice develop metastatic colorectal cancer. Cell 94:703-714.

Zhu Y, Romero MI, Ghosh P, Ye Z, Charnay P, Rushing EJ, Marth JD, Parada LF (2001) Ablation of NF1 function in neurons induces abnormal development of cerebral cortex and reactive gliosis in the brain. Genes Dev 15:859-876. 